\title{
Taxing food: implications for public health nutrition
}

\author{
Martin Caraher ${ }^{1, *}$ and Gill Cowburn ${ }^{2}$ \\ 'Department of Health Management and Food Policy, The Centre for Food Policy, Institute of Health Sciences, City \\ University, Goswell Place, Northampton Square, London EC1 OHB, UK: ${ }^{2}$ BHF Health Promotion Research Group, \\ Department of Public Health, University of Oxford, Old Road Campus, Headington, Oxford OX3 7LF, UK
}

Submitted 12 0ctober 2004: Accepted 10 May 2005

\begin{abstract}
Aim: To set out a policy analysis of food taxes as a way of influencing food consumption and behaviour.

Design: The study draws on examples of food taxes from the developed world imposed at national and local levels. Studies were identified from a systemised search in six databases with criteria designed to identity articles of policy relevance.

Results: The dominant approach identified from the literature was the imposition of food taxes on food to raise general revenue, such as Value Added Tax in the European Union. Food taxes can be applied in various ways, ranging from attempts to directly influence behaviour to those which collect taxes for identified campaigns on healthy eating through to those applied within closed settings such as schools. There is a case for combining taxes of unhealthy foods with subsidies of healthy foods. The evidence from the literature concerning the use and impact of food taxes on food behaviour is not clear and those cases identified are mainly retrospective descriptions of the process. Many food taxes have been withdrawn after short periods of time due to industry lobbying.

Conclusions for policy: Small taxes with the clear purpose of promoting the health of key groups, e.g. children, are more likely to receive public support. The focus of many tax initiatives is unclear; although they are generally aimed at consumers, another focus could be food manufacturers, using taxes and subsidies to encourage the production of healthier foods, which could have an effect at a population level. Further consideration needs to be given to this aspect of food taxes. Taxing food (and subsidies) can influence food behaviour within closed systems such as schools and the workplace.
\end{abstract}

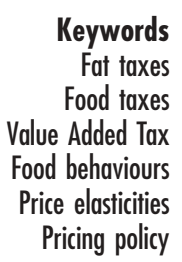

Recent concerns about the burden of diseases such as coronary heart disease, diabetes and obesity, both globally and in the UK, have raised questions about which policy approaches might best address the issues of healthy eating. A World Health Organization/Food and Agriculture Organization report ${ }^{1}$ sees pricing and the cost of healthy foods as being key elements in the prevention equation, driven in part by the rise in diet-related non-communicable diseases. Suggested solutions have ranged from calls for more restrictions on the advertising of energy-dense and fatty foods to the promotion of physical activity ${ }^{2}$. Another proposed solution has been what has become colloquially known as a 'fat tax'. Herein we aim to extend the debate beyond this narrow focus to look at the possible role of taxes on food in general as a populationbased measure to promote healthier eating. Such an approach was reported as under consideration, in early drafts of a report ${ }^{3}$, by the UK Government as a part of a raft of measures to combat unhealthy eating, although the proposals were omitted from the final report ${ }^{4,5}$. While this displays one of the problems of any proposed food tax - its unpopularity - this should not stop us from examining the possible implementation and implications of such a policy. This paper sets out the arguments for and against a food tax, reviews the existing evidence and locates these within a policy context before drawing some conclusions for public health nutrition.

History shows that food taxes have not been popular with citizens throughout the centuries and have been a prime contributor to riots ${ }^{6}$. English history is full of reports of riots where increases in food prices resulted in 'mob behaviour". The European continent similarly has a history of food protests related to increases in food prices, with one of the best documented instances being the 1919 food riots in Italy ${ }^{8}$. Newer food protest has tended to focus on global inequity and unfairness of a food system to indigenous producers ${ }^{6}$.

The background to current increases in the burden of diseases related to food intake can be traced to higher overall energy intake/lower energy expenditure, or some combination of the two, and the consumption of energydense as opposed to nutrient-dense foods. The debates 
polarise between those who favour explanations as rooted in the behaviours of individuals and those who see solutions in more structuralist terms (see Ashton' for the former view and Lang ${ }^{10}$ for the latter). The tension that exists here lies in the anomaly that the structuralists are more likely to support taxes on food, whereas those who see the prime responsibility as individual are more likely to oppose taxes. In reality, the causes are a complex interplay of both food intake and energy expenditure issues.

The present article sets out the existing knowledge and evidence base for a 'food tax' and the implications for public health nutrition. We start by describing the study methodology and then examining what is meant by a food tax before moving on to analysing the evidence of the impact of a food tax on behaviour and concluding with some recommendations for public health nutrition. We have included examples from practice to illustrate the issues.

\section{Study design}

This article results from a request to present a paper on 'Fat taxes: implications for policy makers and consumers' to the 13th Annual Conference of European Food Law in 2004, the overall topic of which was 'The Challenges Ahead: From Obesity to Food Safety'.

The analysis draws on examples of food taxes from the developed world. Studies were identified from existing databases. An Internet search was undertaken of ERIC, MEDLINE, Busine/ss Source Premier, Social Sciences Citation Index (SSCI), SCI-Expanded, and Arts and Humanities Citation Index (AandHCI), using the software packages Reference Manager version 9 (www.refman.$\mathrm{com} /$ ) and Thomson Research Soft Endnote 5 (www.endnote.com/). We employed various combinations of the following search terms in a number of strategies: fat, taxes, food taxes, tax on food and fiscal policy, from material published between the years 1995 and 2003 in English. The search was conducted in January/February 2004. These searches identified several hundred references from the international literature. The following four-fold system of classification was used to rank papers to be included in the literature review according to the level of quality of evidence they presented:

- Level 1: a study, modelling, survey or systematic review, often employing either randomised controlled, quasiexperimental, intervention versus control/comparison group or pre-test/post-test design, with an emphasis on influencing the price of food and food behaviour or choice.

- Level 2: a study, survey or review of dietary/nutritional behaviour allowing the targeting of certain high-risk categories or groups with specific educational or dietary interventions of the aetiology of nutrition-related conditions (obesity, coronary heart disease, diabetes) using monetary or fiscal measures designed to influence healthy eating; a non-systematic review of relevant subject material and professional/government nutritional guidelines or recommendations for fiscal policy related to food.

- Level 3: well-presented qualitative material of the descriptive/anecdotal variety, enabling the formation of pricing strategies for effective healthy eating in settings such as workplaces or schools.

- Level 4: subject relevance but very general in its approach or presented too little data to be of more than general value, e.g. reviews or descriptive accounts of food choice with an element of pricing strategies to influence food behaviour; short topical accounts of different schemes or initiatives, sometimes web-based, and letters, editorials, comments or critiques in journals or newspapers offering informed views or opinions.

These were then subjected to a second level of selection based upon title relevance and/or abstract relevance, which reduced the size of the original search database to a total of some 200 references. We found that few studies met the criteria of level 1 or level 2; the majority were descriptive and generally described policy in action, very often without evaluation or research built in. This produced 34 references for potential inclusion, which were then subjected to a final level of selection based on policy relevance and application. The criteria used here were again four-fold:

1. Contained details of purpose and implementation.

2. Was subject to evaluation/research.

3. The main or a clear part of the tax implementation was food-related.

4. Contained details of the policy implementation of the food tax.

The literature review was systemised to achieve a level of consistency, transparency and rigor ${ }^{11}$. This reduced the number of papers to be requested and read at full paper to eight references in total ${ }^{9,12-18}$. A further two sources (an article and a book) ${ }^{19,20}$ were subsequently identified from scanning reference lists in relevant papers and later included in the final count, resulting in a total of 10 references being the source for the paper and presentation. It should be pointed out that given constraints of time and budget, a full and comprehensive search of the reference/bibliographic lists could not be carried out. We report here only on studies which met the criteria for level 1 and level 2 quality of evidence above and which further met the four policy criteria set out above.

A working paper was presented at the 13th Annual European Food Law Conference, Brussels, 29-30 June 2004, by one of the authors (M.C.); the present paper is based on feedback and discussion from this conference, which contained both representatives from industry and 
government policy-makers ${ }^{21}$. Following the conference we had discussions with a number of government bodies and officials who contacted us asking for more details; we took these as opportunities for further discussion on the issues of food taxes. Some of these individuals have used the ideas presented in the original working paper to inform their own policy development (see the report from the Swedish National Food Administration and the National Institute of Public Health as an example) ${ }^{22}$.

\section{Findings}

\section{What are food taxes?}

What is a food tax? The literature showed that the term is used to cover a range of definitions and purposes. There was some conflation of the terms 'fat tax' and 'food tax', and many of the articles identified initially in the first scan were reactions and commentaries against the imposition of a 'fat tax' or 'sin tax'. These were often responses from the food industry and political conservatives, and were focused on choice and freedom and the danger of the nanny state. The majority of the literature talked of 'fat taxes' in a conceptual or theoretical way as opposed to being empirically based. The focus of many of the articles was on personal freedom, using fat taxes and restrictions on tobacco smoking as examples of restrictions on personal freedom. These generally fell into level 4 ranking for quality of evidence and were neither evidenced-based nor directly policy-relevant; as a body of work, however, they displayed the objections to the imposition of a food or fat tax. One of the exceptions was the article by Ashton?, which partially addressed food taxes as well as advertising bans and was evidence-based.

\section{Some example of taxes levied on food}

The imposition of taxes on food was generally in one of the following four ways:

1. By raising general revenue as in Valued Added Tax (VAT) in the European Union (EU) or a general service tax (GST) as in Australia.

2. By extending VAT to some foods such as those high in fat content and using this hypothecated revenue to fund prevention initiatives (i.e. the so-called 'fat tax').

3. By imposing taxes directly on categories of foodstuffs to impact directly on behaviour with an additional function identified for revenues, with some or all or the revenues being earmarked for prevention activities.

4. By imposing taxes directly on certain foodstuffs with the intent of impacting directly on behaviour, with no specific function for revenues.

With approach number 3 above, the examples we found were generally more concerned with raising revenues as opposed to directly influencing behaviour, or the impact on behaviour was not measured or evaluated. The first approach was the most common approach to taxes on food, with examples of taxes on food to raise general revenues without the intention of influencing food behaviour. Nevertheless they are presented here as ways we can learn from. Regulatory regimes such as VAT sometimes target food but they are not conceived of as a food tax per se: they are really a general tax which happens to include food. Their current mechanisms are so complex that their impact on healthy choice is hard to determine. In the UK, VAT is added to some 'treat foods' (such as ice cream, carbonated drinks and confectionery) whereas other treat foods (such as cakes, cake bars, Jaffa cakes, cookies and plain biscuits) are zero-rated. But in the labyrinthine regulations that cover VAT in the UK, the addition of 'chocolate buttons' to any of these zero-rated items would result in VAT being applied. Across the EU the situation is even more complex with no uniformity of rates. Some countries have a single rate of VAT for foodstuffs (e.g. Denmark at 25\%), while others have two (e.g. the UK at $0 \%, 17.5 \%$ ) or three (e.g. Ireland at $0 \%$, $4.3 \%, 13.5 \%)$. Spain, Ireland, Italy and Luxembourg impose what is known as a 'super-reduced' VAT (less than 5\%) on food products. In Ireland, a zero rate is applied for food and drink for human consumption, although this excludes soft drinks, ice cream and confectionery $^{12}$.

In Australia, a new Goods and Services Tax (GST) was introduced on most products and services in 2000 to replace a number of indirect taxes. Basic foods were excluded as were hot takeaway foods, prepared foods, fast foods, confectionery, savoury snacks, bakery products, ice cream and biscuits (J Coveney, personal correspondence, 2004).

Questions arise as to the mechanism that can be used to apply general taxes to the area of food to influence food choice either directly or indirectly ${ }^{13}$. Suggestions include using the mechanism of sales taxes such as VAT or GST and extending them to cover those foods which are currently exempt but have a high fat content, such as butter, whole milk and biscuits, or categories of food such as snacks or those consumed as takeaways. Another way is to define unhealthy foods, non-essentials or non-core items, foods sold or prepared in certain ways. In practice this was found to be applied through distinguishing 'wants' as opposed to 'needs' - so certain categories of products (like carbonated drinks) were not classed as needs or essential to the requirements of daily living ${ }^{15}$. There is such a precedent already established with VAT. In the EU, Belgium, Germany, Ireland, Italy and the UK apply a lower rate of VAT to drinks considered essential such as tea, coffee and milk and a higher rate on drinks that are not, such as soft drinks. However, France, Spain and Sweden apply the same VAT rate across all drink categories ${ }^{14}$.

The imposition of food taxes was also seen by some as sending an important symbolic message to the public ${ }^{15}$. In much the same way that many anti-smoking initiatives have been important for their symbolic value, the value of 
a food tax may be to send a clear message that the government is concerned about the issues. Despite references to the possibility of Ireland implementing a fat $\operatorname{tax}^{3,15}$, the views of the then Irish Minister for Health were reported ${ }^{23}$ as:

The Minister for Health and Children has ruled out the introduction of a tax in junkfood saying 'long terms strategies' are needed to tackle Ireland's growing rates of obesity.

This comes from within a country and from a minister who successfully introduced a smoking ban in the workplace, and some have noted that an opportunity has been missed to show high-level commitment to the promotion of healthier eating.

Many of the examples illustrated how the state collects taxes from foodstuffs rather than demonstrating how food taxes might be applied to influence food behaviour and consumption. They show that food is subject to a tax of sorts, although its purpose is to raise general revenues. In Sweden and Norway, imports of soft drinks and confectionary are subject to VAT of $7.14 \%{ }^{12,13}$. In Norway, this can be related to their overall national food and nutrition policy which sets out four main goals:

1. To encourage a health-promoting diet, reducing fat consumption, especially saturated fats, and replacing them with polyunsaturated fats, whole grains and vegetables.

2. To promote domestic food production and reduce food imports, increasing national self-sufficiency from $39 \%$ of total calories to $52 \%$ by 1990 .

3. To promote agricultural development in the country's less advantaged areas and outlying regions, with due regard to preserving the environmental resource base.

4. To contribute to world food security by promoting production and consumption in poor countries.

So, in Norway (not part of the EU), taxes are related to wider environmental and social issues and are (as currently devised) closer to a 'calorie' tax than a 'fat' tax, as some foods will naturally be high in fat and others low and these may not be an adequate description of their healthiness or otherwise ${ }^{12}$.

In the USA there are numerous examples of local taxes at a city or state level which are generally concerned with generating income as opposed to influencing behaviour; these are generally applied to categories of food or drink as opposed to being based directly on the nutritional content of food. Jacobson and Brownell ${ }^{15}$ report that the soft drinks and snack taxes imposed in 18 states and one major city in the USA raise approximately $\$ 1$ billion annually. For example, Arkansas raised $\$ 40$ million annually from a tax of about 2 cents per 12-Oz can of soft drink. In Maryland in 1992 the imposition of taxes on snack foods led to a reported $\$ 500000$ drop in sales for Frito-Lay (the potato crisp maker). California introduced a snack food tax in 1991 where popped popcorn and Milky
Way bars were taxed but unpopped popcorn and frozen Milky Way ice cream bars were exempt. An entire cake was tax-free but a slice taxable. This tax resulted in an estimated $10 \%$ drop in the sales of snack foods; price elasticity was estimated at -1.21 , indicating that demand may be sensitive to small increases in the price of snack foods. Revenue generated from the tax was not significant, jobs were threatened and under pressure from the food industry the tax was repealed.

In their report on obesity, JP Morgan ${ }^{16}$ outline the following four examples of food taxes (p. 19):

- Arkansas, Washington and West Virginia impose special taxes on soft drinks; Minnesota charges sales tax on candy, chewing gum and ice cream; and Texas imposes a candy tax.

- A Maryland proposal would make it illegal for restaurants that sell soft drinks not to sell sugar-free beverages as well (violators would face a $\$ 500$ fine).

- In Connecticut, a bill was filed to repeal a $6 \%$ sales tax exemption for confectionery sold to college cafeterias, senior centres and day-care centres.

- California tried to raise taxes to finance programmes to fight obesity. In early 2002 California attempted to impose a levy of $\$ 0.21$ per gallon of soda and $\$ 2$ per gallon of concentrate. This 'soda tax' would have generated $\$ 342$ million a year in revenues to be shared between schools that stopped selling soda on their campuses, the State Department of Health Services to promote nutrition and exercise, and hospitals/clinics/ trauma centres. The bill was amended several times before being defeated by the Senate Education Committee in spring 2002.

The above examples of schemes show that most of the taxes are imposed on categories of foods (soft drinks/candy or sweets) as opposed to being related to the nutrient content of individual foods, and that they are imposed in micro-situations such as schools or canteens, vending machines or fast-food restaurants. In general, taxes are applied as a flat rate or as a percentage of the retail price. As an alternative approach, food advertising could be the focus of taxation on the basis that the majority of existing food advertising is promoting the types of foods that are implicated in snacking culture, one of the major contributors to rising obesity ${ }^{13,15,17}$.

\section{Evidence for the influence of food taxes on behaviour}

The literature identified under this heading consisted of two papers, both of which were based on a modelling approach $^{13,17}$. Both of these were judged to fit into level 1 quality of evidence. A paper by Marshall ${ }^{17}$ claimed that the imposition of a fiscal food tax could help prevent 1000 deaths a year in the UK. Marshall based his analysis on the premise that VAT on whole milk, cheese, butter, etc. could reduce premature deaths by $900-1000$ per year. To do this 
he made some assumptions about their price elasticities, suggesting that whole milk has an elasticity of -1.0 since it has close substitutes in the form of skimmed and semi-skimmed milk, whereas cheese (estimated elasticity -0.5) and butter (-0.7) have fewer direct substitutes and so have lower price elasticities. Responders to this article debated the impact of tax on food choice and saw the solution in the development of a new generation of functional foods for consumers, focusing on the negative, regressive impact that such taxes have on the poor ${ }^{24}$.

Marshall's analysis was taken further by Leicester and Windmeijer ${ }^{13}$ from the Institute for Fiscal Studies. They modelled the impact of a fat tax on nutrients purchased and the financial implications. Across all income groups, the amount of nutrients purchased changes little between those on high incomes and those on low incomes, because the amount of fat, sodium and cholesterol consumed does not vary much between the different income groups. They found that the impact of an average fat tax across the income quintiles would be as seen in Fig. 1. They also suggested that contexts may be important in the imposition of taxes, a similar finding to that of French and colleagues ${ }^{18,19}$. So for example it might be easier to control for pricing variations within a setting such as a school or university.

Figure 1 translates into the following:

- The very poorest $2 \%$ of the population with incomes of less than $£ 36$ per week would spend $0.7 \%$ of their total income on the fat tax.

- People in the middle of the income distribution with incomes around £140 per week would pay around $0.25 \%$ of their total income.

- The very richest with incomes above $\$ 519$ per week would pay less than $0.1 \%$ of their income.

Leicester and Windmeijer ${ }^{13}$ (p. 15) concluded that:

[T]he very poorest perhaps consume slightly less fat and cholesterol, but they also have particularly low incomes such that even a small tax would constitute a fairly high average tax rate.

While Marshall ${ }^{17}$ did build a behavioural element into his calculations, this is absent from the Institute of Fiscal

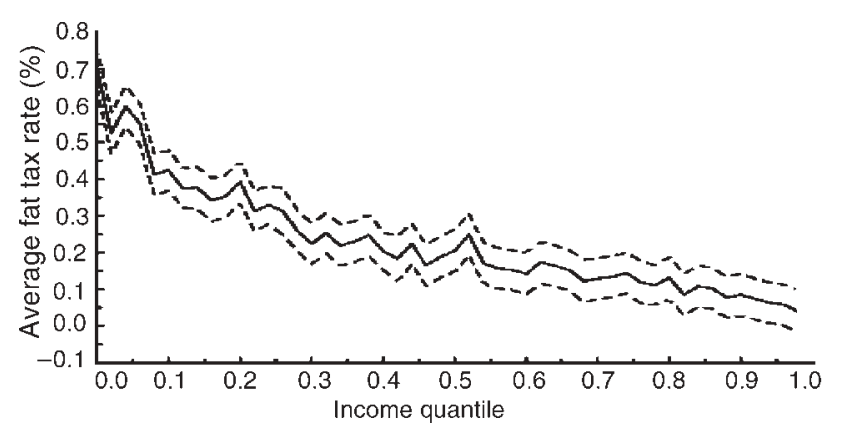

Fig. 1 Distribution effects of a 'fat tax' (from Leicester and Windmeijer ${ }^{13}$ based on calculations from the National Food Survey)
Studies model so their conclusions need to be treated with caution as the demand for food is only partially influenced as a result of price changes. Food is more complicated than other items such as cigarettes because, for example, of the wide variety of product substitutes and different products (e.g. low-fat milk or margarine) available to consumers. What is clear from the paper is any food tax is regressive in that it impacts on the poor more than the well-off, as the proportion of a household budget allocated to all foods tends to decline with increasing income.

\section{Discussion: policy architecture}

There was no evidence of wide-scale use of food taxes at national government level to influence eating behaviour; this was in contrast to the use of taxes on food to raise general revenues. Taxes are levied on food, this is clear, but the purpose is not as to act as a 'food tax' to influence food behaviour per se, but as a general revenue generator - as in the case of VAT. Analysis of the limited literature available shows that 'food taxes' could be adopted or used for any one the following four purposes:

1. To encourage healthy eating by consumers.

2. To diminish the consumption of certain foods or types of foods, e.g. snack or fast foods.

3. To direct food manufacturers towards the production and manufacture of more healthy options.

4. As an anti-obesity measure.

As the obesity crisis grows, calls for a tax to halt obesity have become more vocal. The calls for a tax on 'unhealthy foods' have taken place against a background of increasing expenditure among all groups, including children, on snack foods ${ }^{2,4,25}$. This raises the issue of taxing categories of foods, such as snack foods, as opposed to making decisions purely on their nutrient or calorific content. This would allow, at least theoretically, key behaviours such as snacking to be targeted through the mechanism of food categories.

Arguments for regulating snack foods come from work such as that of Cutler et $a l .{ }^{26}$, who using US data locate the rise in the percentage of overweight or obese adults (around 40\% in the early 1960 s to over 60\% in 1999) to an increase in eating between meals, a decline in the quality of nutrient intake, and the low cost of many snack and energydense foodstuffs. Much snacking is in the form of energydense and processed high-fat foods, and these are one of the categories of food that many advocate should be taxed. Similarly, data from UK market research shows that of nine million young consumers, only $4 \%$ do not engage in snacking after school. In part this may be explained by the wide availability and cheap cost of snack foods and the increased spending power of children. Mintel $^{27}$ said that:

In a relatively expansive economy, the level of children's pocket money increased significantly during the second half 
of the 1990 s and into the new millennium. Wall's Monitor, which tracks trends in pocket money, indicates that children, on average, have around $£ 6.50$ weekly to spend (2001 data). The older, more independent school child who is able travel bome from school alone thus has the means to purchase snack items in addition - or as an alternative to consuming snacks provided for him/her at home.

National Statistics in the UK reported on the consumer power of young children, with those aged 7-15 years spending £12.30 per week on average ${ }^{28}$. Girls were more likely than boys to spend their money on clothing and footwear, and personal goods, such as toiletries and cosmetics. Boys were more likely than girls to spend their money on food and non-alcoholic drinks, and leisure goods, such as computer games, CDs and videos. But both groups spent up to one-third of their money on food and drink outside the home. Figure 2 gives a breakdown of these spending patterns. More recent data from the UK showed that the amount children spend on the way to school has increased to 1.01 from 77p in 2002 and a further $74 \mathrm{p}$ is spent on the way home; the majority of this is spent on the four Cs of 'confectionery, chocolate, crisps and canned drinks'. This out-of-school spend can be contrasted with the amount provided by parents to pay for school meals, which is $£ 1.84^{29}$. Much of this is used to justify the imposition of taxes or restrictions on snack foods, but the evidence for the impact of such taxes is rarely considered.

The application of taxation to categories of food as opposed to the nutrient content of the food itself is a pragmatic approach to difficult measurement issues and is often based on the notion that snacks, soft drinks and at least some foods sold from fast-food outlets are unnecessary or do not constitute basic needs. Jacobsen and Brownell ${ }^{15}$ make the point that:

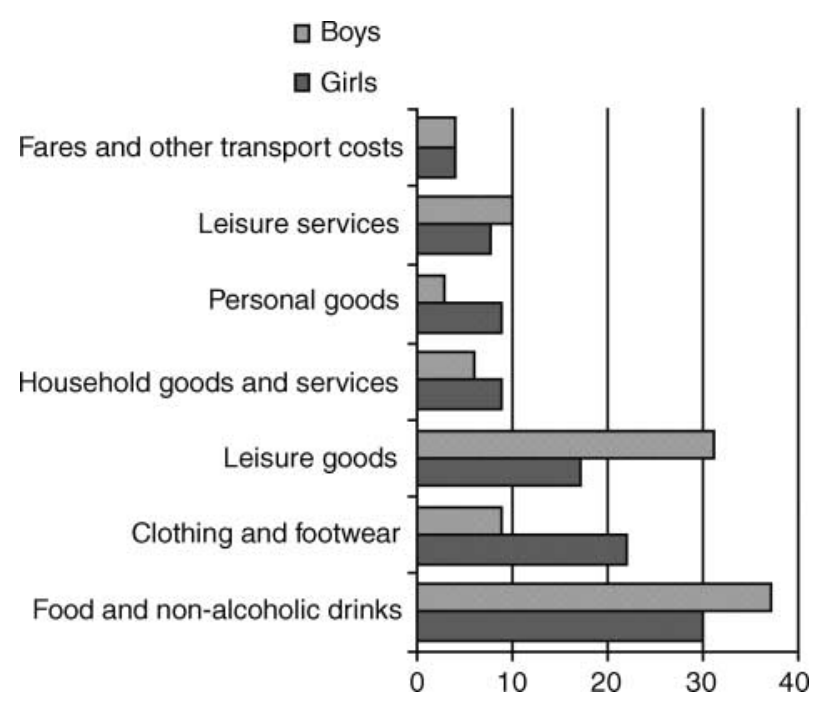

Fig. 2 Expenditure of children aged 7-15 years, percentage of income spent on different goods (from National Statistics ${ }^{28}$ )
[L]egislative bodies find it more practical to tax well-recognised categories of food that play little useful role in nutrition. Soft drinks and snack foods typically add unneeded calories to the diet or replace nutritious foods, such as low-fat milk or fruit, without providing significant levels of nutrients.

The imposition of food taxes seems to be easier in controlled situations such as schools or canteens. Findings from a systemised review of food in schools confirm that taste, convenience and price were the prime determinants of children's food choice ${ }^{30}$. Manipulation of all three is important if food choice is to be influenced. So within closed systems such as canteens in workplaces or schools it may be possible to experiment with subsidies for health foods and 'taxes' on unhealthy ones. This makes us think that the best application of pricing control is within closed systems such as hospitals, workplaces and schools, where incentives (subsidies) and availability can be balanced with deterrents (taxes/higher costs).

Of course, policy development is only partially driven by evidence; the appeal and political consequences of any policy are also important for any government, as are the practicalities of implementation and enforcement. Brownell and Horgen ${ }^{20}$ suggest that:

[T]axation as a deterrent to behaviour is less appealing than using tax revenues to encourage positive changes.

However, they seem to base this assumption on the political appeal (or otherwise) of food taxes rather than empirical evidence as to their direct impact on behaviour. The House of Commons Select Committee ${ }^{4}$ also came to a similar understanding when they concluded (p. 64) that:

[I]ncreases to the prices of unbealthy foods need to be balanced by the introduction of measures to lower the price of bealthy foods, making them affordable to all.

Such comments point to the lack of political will to implement food taxes. Such political unwillingness can be attributed to two key influences - the power of the food industry and the suggested regressive nature of any tax and the fear that it may impact on the poor more than the rich $^{13,15,20}$.

Calls for the use of food taxes as anti-obesity measures, we suggest, are not sufficiently focused, and what is proposed is often done without due weight being given to the mechanisms by which food taxes might operate and the decisions that individual consumers make in food choice. Taxation can be used in either a direct or an indirect way to influence choice. Price is certainly one issue in food choice, but far from the only one.

For the food industry, the reality is that 'good' foods are bad commodities with low profit margins while 'bad' foods are good commodities with high margins ${ }^{31}$. Food growing, the food industry and government policy and subsidies, as well as existing taxation systems, support an unhealthy food system. Simply taxing the end product 
may be insufficient; there is a need to look at the whole food chain from farm through production to distribution in order to ensure that any system of food taxes is systematic and sustainable ${ }^{32}$. Taxes may be better applied directly to production or manufacturing to encourage producers and manufacturers to change their processes, although it is likely that such taxes would still be passed on to the consumer. A report from UBS Warburg ${ }^{33}$ notes that businesses such as soft drinks bottlers already pay business and other taxes, and that an additional tax on their product is unfair and discriminatory, anti-competitive and anti-business. The same report reiterates the regressive and unpopular nature of such taxes with voters, suggests that the implementation of such taxes increases bureaucracy, and concludes that:

The introduction of new taxes is always unpopular. Regulating advertising and marketing and labelling is politically less sensitive and, in our view, is a more likely route initially.

Similarly, the JP Morgan ${ }^{16}$ report on obesity rates the likelihood of food taxes being implemented as low compared with further restrictions on labelling and advertising. In a forecasting report on the food industry and fat, Curry and Kelnar maintain that the industry is currently dominated by addressing policy issues related to obesity by disputing critical research and commissioning their own, as opposed to wide-scale changes or diversifying product lines ${ }^{34}$.

As shown above, several food tax schemes have been withdrawn as a result of industry pressure and popular concern. Although there is an undoubted regressive impact of a food tax, the full implications have not been trialled and are poorly understood. Influencing food pricing may also involve lowering the price of healthy foods, rather than a sole focus on increasing the price of less healthy ones, and little is currently known about the impact of such an approach across income levels. According to Leicester and Windmeijer $^{13}$, unless the tax makes the food more expensive than a desirable alternative - rather than merely slightly less expensive - any behavioural outcome is likely to be muted. There is also the assumption that a switch from a more taxed (and therefore expensive) food is informed by the individual knowing what the alternatives are. This assumes that food choice is based on a rational ordered approach. In fact, decisions around food choice are often made using a range of complex processes ${ }^{35}$.

The imposition of food taxes is often promoted as one way of raising revenue for specific health promotion or social marketing activities (hypothecated revenues). Our argument against such hypothecated initiatives is that such an approach would be largely ameliorative as opposed to preventive and is a reaction to the promotion of unhealthy foods. Their importance could, however, be symbolic and be about a clear public health message. Initiatives such as social marketing campaigns funded from such revenue could not hope to compete with any real weight against food industry marketing on a $£$ for $£$ or $€$ for $€$ basis, and it is likely that the funded programmes would focus downstream on the individual consumer rather than upstream on the food companies dominating unhealthy production and marketing in the food system. This focus on downstream approaches ${ }^{36}$ suits the industry philosophy of focusing on the individual. The lessons from tobacco control suggest that hypothecated funding needs to be used to tackle structural issues such as growing practices and not just spent on health education campaigns ${ }^{37}$. The food industry inevitably complains about contributing to campaigns which it sees as anti-competitive ${ }^{38}$.

\section{Conclusions}

The lessons from this overview of food taxes for policy implementation are that:

- Small taxes with clear and unambiguous intent used to promote the health of key groups, such as children, are more likely to receive public support; although in our view they may, on their own, be an ineffective means of tackling the problems with overeating and consumption of energy-dense foods.

- The food industry is 'likely' to oppose any idea of taxes. Therefore political commitment to the introduction of such taxes needs to be clearly stated and agreed.

- The focus of many taxed initiatives is unclear, although they are generally aimed at the end consumer. Another focus could be food manufacturers, using taxes and subsidies (stick and carrot approaches) to encourage them to produce healthier foods.

- Food taxes as a stand-alone initiative to counteract obesity are likely to fail. They are, on their own, a simple solution to a complex problem. They should be considered alongside other policy initiatives such as restructuring of food subsidies though mechanisms such as the Common Agricultural Policy and restrictions on advertising. It is not just food taxes that need to be considered but also the corresponding issue of subsidising the growth, production and consumption of healthier foods.

- More research is needed on the impact of food taxes on food choice especially among low-income consumers, children and the area of impulse and snack buying.

- Taxing food (and subsidies) should be considered within closed systems such as schools, canteens and the workplace. The evidence for such approaches has some basis in the literature.

- The purpose of a food tax can be based on a population approach as opposed to an initiative designed to change individual behaviour. Food taxes imposed on food manufacturing could influence the production of foodstuffs, which could have a population effect. Further consideration needs to be given to this aspect of food taxes. 
We conclude that the focus on a 'food tax' may be misplaced and instead recommend looking at pricing policies that have the dual impact of discouraging key behaviours and encouraging others - in other words, a mix of 'taxes' and subsidies.

\section{Acknowledgements}

We would like to thank all of those who contributed to our thoughts on this issue and those who engaged with the paper and ideas presented at the Agra Europe conference in Brussels. Thanks are also due to the anonymous reviewer for the clarity of their comments.

Source of funding: none.

Conflict of interest: none declared. M.C. received payment for travel expenses (£224) and accommodation during the conference in Brussels from Agra Europe (London) Ltd.

\section{References}

1 World Health Organization (WHO)/Food and Agricultural Organization. Diet, Nutrition and the Prevention of Chronic Diseases. Technical Report Series No. 916. Geneva: WHO, 2003.

2 Hawkes C. Marketing Food to Children: The Global Regulatory Environment. Geneva: World Health Organization, 2004 .

3 The Cabinet Office. Personal Responsibility and Changing Behaviour: The State of Knowledge and Its Implications for Public Policy. London: The Cabinet Office, Prime Minister's Strategy Unit, 2004

4 House of Commons Health Committee. Obesity: Third Report of Session 2003-04. London: The Stationery Office, 2004.

5 Halpern D, Bates C, Beales G, Heathfield A. Personal Responsibility and Changing Behaviour: The State of Knowledge and Its Implications for Public Policy. London: The Cabinet Office, Prime Minister's Strategy Unit, 2004.

6 Caraher M. Food protest and the new activism. In: John S, Thomson S, eds. New Activism and the Corporate Response. Basingstoke: Palmgrave, 2003; 185-205.

7 Thompson EP. The moral economy of the English crowd in the eighteenth century [Chapter 4]. Customs in Common. Harmondsworth: Penguin Books, 1993.

8 Helstosky C. Garlic and Oil Food and Politics in Italy. Oxford: Berg, 2004.

9 Ashton D. Food advertising and childhood obesity. Journal of the Royal Society of Medicine 2004; 97(2): 51-2.

10 Lang T. The public health impact of globalisation of food trade. In: Shetty P, McPhearson K, eds. Diet, Nutrition and Chronic Disease: Lessons from Contrasting Worlds. . London: John Wiley and Sons, 1996.

11 Hart C. Doing A Literature Review: Releasing the Social Science Research Imagination. London: Sage, 1998.

12 European Commission Directorate-General Taxation and Customs. VAT rates applied in the member states of the European Community [online]. Brussels: European Commission, 2003. Available at http://europa.eu.int/comm/ taxation_customs/publications/info_doc/taxation/tva/ taux_tva-2003-5-1_en.pdf. Accessed 13 July 2004.

13 Leicester A, Windmeijer F. The 'Fat Tax' Economic Incentives to Reduce Obesity. London: Institute for Fiscal Studies, 2004.

14 World Health Organization (WHO). Food and Health in Europe: A New Basis for Action. European Series No. 96. Copenhagen: WHO, 2004.
15 Jacobson M, Brownell K. Small taxes on soft drinks and snack foods to promote health. American Journal of Public Health 2000; 90(6): 854-7.

16 Morgan JP. Food Manufacturing: Obesity the Big Issue. London: JP Morgan European Equity Research, 2003.

17 Marshall T. Exploring a fiscal food policy: the case of diet and ischaemic heart disease. British Medical Journal 2000; 320(7230): 301-5.

18 French SA, Jeffery RW, Story M, Hannan P, Snyder P. A pricing strategy to promote low-fat snack choices through vending machines. American Journal of Public Health 1997; 87(5): 849-51.

19 French SA, Jeffery RW, Story M, Breitlow KK, Baxter JS, Hannan $\mathrm{P}$, et al. Pricing and promotion effects on low-fat vending snack purchases: the CHIPS Study. American Journal of Public Health 2001; 91(1): 112-7.

20 Brownell KD, Horgen KB. Food Fight: The Inside Story of the Food Industry, America's Obesity Crisis, and What We Can Do About It. Chicago, IL: Contemporary Books, 2004.

21 Caraher M. Fat taxes: implications for policy makers and consumers. Paper presented at the 13th Annual European Food Law Conference (The Challenges Ahead: From Obesity to Food Safety), Brussels, 29-30 June 2004.

22 Swedish National Food Administration and National Institute of Public Health. Background Material for the Action Plan Concerning Healthy Dietary Habits and Increased Physical Activity. Uppsala: Swedish National Food Administration, 2005.

23 Humphreys J. Martin rules out tax on junk food. Irish Times, 11 March 2004; 3.

24 Kennedy E, Offutt S. Alternative nutrition outcomes using a fiscal food policy [Commentary]. British Medical Journal 2000; 320(7230): 305-9.

25 Hitchman C, Christie I, Harrison M, Lang T. Inconvenience Food: The Struggle to Eat Well on a Low Income. London: Demos, 2002.

26 Cutler D, Glaeser E, Shapiro J. Why have Americans become More Obese? Research Working Paper 9446 [online]. Cambridge, MA: National Bureau of Economics, 2003. Available at http://www.nber.org/papers/w9446. Accessed 13 July 2004.

27 Mintel. After School Snacking: Intelligence Report. London: Mintel, 2003.

28 National Statistics. Special Focus in Brief: Children. London: National Statistics, 2002.

29 Sodexho. The Sodexho School Meals and Lifestyle Survey 2005. Surrey: Sodexho, 2005.

30 Caraher M, Cowburn G, Currie E. Food in School: The Evidence. A Report to the Food in Schools Initiative, Department of Health. London: Department of Health Management and Food Policy, City University, 2003.

31 Caraher M, Coveney J. Public health nutrition and food policy. Public Health Nutrition 2004; 7(5): 591-8.

32 Barling D, Lang T, Caraher M. Food, social policy and the environment: towards a new model. Social Policy and Administration 2001; 35(5): 538-58.

33 UBS Warburg. Global Equity Research: Absolute Risk of Obesity. London: UBS Warburg, 2002.

34 Curry A, Kelnar R. Fat is a Strategic Issue. London: Henley Centre, 2004.

35 Connor M, Armitage CJ. The Social Psychology of Food. Buckingham: Open University Press, 2002.

36 McKinlay JB, Marceau LD. Upstream health public policy: lessons from the battle of tobacco. International Journal of Health Services 2000; 30(1): 49-69.

37 Jha P, Chaloupka F. Tobacco Control in Developing Countries. Oxford: Oxford University Press, 2000.

38 Nestle M. Food Politics: How the Food Industry Influences Nutrition and Health. Berkeley, CA: California State University Press, 2002. 